\title{
ANÁLISIS ECONÓMICO DE LA RESPONSABILIDAD BANCARIA FRENTE A LOS FRAUDES ELECTRÓNICOS: EL RIESGO PROVECHO, EL RIESGO CREADO Y EL RIESGO PROFESIONAL*
}

\section{LAW AND ECONOMICS OF THE BANKING LIABILITY FROM ELECTRONIC FRAUDS: THE BENEFIT RISK, THE CREATED RISK AND THE PROFFESIONAL RISK}

\author{
Alejandro Rodríguez Zárate** \\ Fecha de recepción: 21 de octubre de 2013 \\ Fecha de aprobación: 16 de diciembre de 2013 \\ Disponible en línea: 30 de junio de 2014
}

\section{Para citar este artículo / To cite this article}

Alejandro Rodríguez Zárate, Análisis económico de la responsabilidad bancaria frente a los fraudes electrónicos: el riesgo provecho, el riesgo creado y el riesgo profesional, 128 Vniversitas (2014). http://dx.doi.org/10.11144/ Javeriana.VJ128.aerb

doi:10.11144/Javeriana.VJ128.aerb

\footnotetext{
Artículo de investigación resultado de las actividades del centro de Estudios de Derecho y Economía de la PUJ.

** Abogado de la Universidad Externado de Colombia, especialista en derecho financiero de la Universidad del Rosario, especialista en derecho comercial de la misma universidad, especialista en economía de la Universidad de Los Andes, magíster en derecho económico de la Pontificia Universidad Javeriana. Profesor de análisis económico del derecho en la Maestría de Derecho Económico de la Pontificia Universidad Javeriana, y miembro del Centro de Estudios de Derecho y Economía de la misma universidad. Correo electrónico: arodriguez@ lae.com.co.
} 


\section{RESUMEN}

En el presente escrito se aborda el análisis de la responsabilidad bancaria frente a los fraudes electrónicos cometidos en contra de sus clientes, bajo el régimen de responsabilidad subjetiva y el régimen de responsabilidad objetiva, para posteriormente efectuar el análisis de la eficiencia en cada uno de ellos, bajo algunas herramientas microeconómicas.

Con fundamento en ello, en un primer acápite se aborda un análisis jurídico, principalmente a partir de la regulación colombiana y algunas propuestas desarrolladas por la doctrina a partir de las teorías del riesgo provecho, el riesgo creado y el riesgo profesional, para en un segundo apartado, y partiendo de una breve descripción del mercado financiero colombiano y de los agentes en él involucrados, efectuar un análisis de eficiencia bajo los criterios de Pareto y Kaldor-Hicks.

Se concluye entonces que la responsabilidad objetiva de las entidades bancarias por fraudes electrónicos no es viable bajo las teorías antes mencionadas, y que tampoco constituye una opción económicamente eficiente.

Palabras clave: análisis económico; responsabilidad civil; responsabilidad bancaria; fraudes electrónicos 


\section{ABSTRACT}

This paper contains, firstly, an approach of the banking liability from electronic frauds committed against their clients, under both the fault liability and strict liability regimes. Following this topic, there is an efficiency analysis of the same issues with microeconomic tools.

With those basis, in the first part there is only a legal analysis, focused in the Colombian law and some proposals of different authors from the benefit risk, created risk and professional risk theories; the second part begins with a brief description of the Colombian financial market and its agents, and concludes with the efficiency analysis under the Pareto and Kaldor-Hicks criteria.

The author concludes that the strict liability is not possible in the case analyzed, under the Colombian law, and it is not either an efficient option.

Keywords: law and economics; liability; banking liability; electronic frauds

\section{SUMARIO}

INTRODUCCIÓN.- I. LA RESPONSABILIDAD BANCARIA FRENTE A LOS FRAUDES ELECTRÓNICOS.- A. Régimen tradicional: responsabilidad subjetiva.- B. Planteamiento bajo el régimen de responsabilidad objetiva.- II. ANÁLISIS ECONÓMICO DE LA REGLA DE RESPONSABILIDAD OBJETIVA.- A. El mercado financiero colombiano.- B. Fallas del mercado.- 1. Selección adversa.- 2. Riesgo moral.- 3. Una aproximación a la regla de Hand.- 4. La negligencia contribuyente y la negligencia comparativa.- CONCLUSIONES. 


\section{INTRODUCCIÓN}

Por su propia naturaleza, derivada del hecho de administrar recursos captados del público, los mercados financieros suelen tener fuertes barreras de entrada y como consecuencia de ello se erigen normalmente en oligopolios. No obstante, lograr un parámetro claro de definición en torno al modelo oligopólico que en cada uno de los escenarios pueda llegar a adquirir el mercado financiero es, en realidad, casi imposible.

Para el caso colombiano, es sensato considerar que el mercado financiero adopta el modelo de Bertrand ${ }^{1}$, pues aunque se presenta un grupo más o menos reducido de oferentes, tienen una marcada competencia en precios sobre productos relativamente homogéneos y no existe colusión.

De otro lado, desde la arista de la demanda, los servicios financieros tienden a ser inelásticos con respecto al precio, cuando se trata de servicios en masa, normalmente prestados a personas naturales no profesionales en la materia o, al menos, con una racionalidad limitada por cuenta de la ausencia de conocimientos previos suficientes en materia financiera.

El punto de vista planteado anteriormente nos permite marcar el derrotero para el análisis de la conducta de los agentes dentro del mercado financiero colombiano y, sobre todo, del marco regulatorio en materia de protección al consumidor, en este caso, por responsabilidad en presencia de fraudes electrónicos.

En tal sentido, recientemente se ha planteado la posibilidad de endilgar responsabilidad de carácter civil a las entidades bancarias, como emisoras de los medios electrónicos de pago, por virtud de los fraudes electrónicos, bajo las teorías de responsabilidad objetiva fundadas principalmente en el riesgo creado ${ }^{2}$. De igual forma, se

1 Para mayor profundidad en el modelo oligopólico de Bertrand, cfr. Robert Frank, Microeconomía Intermedia, $7^{\mathrm{a}}$ ed., McGraw Hill, México, 429-430 (2009).

2 Cfr. Héctor García Santiago, Los medios de pago: evolución y responsabilidad de sus emisores, en Estudios jurídicos sobre comercio electrónico, Pontificia Universidad Javeriana - Cámara de Comercio de Bogotá, Bogotá D. C., 187-248 (2006); Tribunal Superior del Distrito Judicial de Bogotá, Sala Civil. Radicación 110013103008200101281-01 (M.P. Ana Lucía Pulgarín Delgado. 20 de abril de 2006); aun cuando no corresponde estrictamente a responsabilidad civil de entidades bancarias por cuenta de fraudes electrónicos, la sentencia de la Corte Suprema de Justicia, Sala de Casación Civil. Expediente 11001-3103-038-2001-01054-01 (M.P. William Namén Vargas. 24 de agosto de 2009), abre la compuerta a un amplio espectro de escenarios en el que la responsabilidad civil bajo el régimen de culpa presunta muta a responsabilidad 
ha promulgado una serie de normas de protección al consumidor financiero que aunque no parten del mismo planteamiento, conducen en la práctica a consecuencias similares ${ }^{3}$.

El propósito del presente escrito es, entonces, abordar el análisis de la responsabilidad bancaria por fraudes electrónicos bajo el prisma jurídico, para posteriormente darle el matiz derivado de las herramientas microeconómicas y a partir de allí lograr una conclusión en torno a la eficiencia o ineficiencia de dicho régimen de responsabilidad.

Ese es, entonces, el propósito del presente escrito, sin pretender con el mismo agotar el debate en torno a un tema tan álgido e interesante como el que se pretende abordar, sino por el contrario, alimentar la discusión que permita desarrollar soluciones acertadas a las problemáticas que genera la dinámica económica y social.

\section{LA RESPONSABILIDAD BANCARIA FRENTE A LOS FRAUDES ELECTRÓNICOS}

Antes de abordar los regímenes de responsabilidad a que puede verse abocado el emisor de los medios de pago, conviene brindar algún alcance a la expresión "fraude electrónico" con miras a determinar en forma precisa el análisis que a partir del presente acápite se aborda.

En primer lugar, es importante señalar que hacemos referencia aquí a los fraudes que puedan referirse a medios de pago de carácter electrónico e individual, entre otros, las tarjetas débito, las tarjetas

objetiva. De hecho, el punto no es para nada pacífico y dio lugar a la aclaración de voto de los magistrados Ruth Marina Díaz Rueda, César Julio Valencia Copete y Edgardo Villamil Portilla, por considerar que en el ámbito legislativo colombiano, aún no puede darse dicho tránsito en el régimen de responsabilidad.

3 Ley 1328 de 2009. Por la cual se dictan normas en materia financiera, de seguros, del mercado de valores y otras disposiciones. 15 de julio de 2009. D.O. No. 47.411; Superintendencia Financiera de Colombia. Circular Externa 052 de 2007. Sobre requerimientos mínimos de seguridad y calidad en el manejo de información a través de medios y canales de distribución de productos y servicios para clientes y usuarios. 25 de octubre de 2007; Superintendencia Financiera de Colombia. Circular Externa 042 de 2012. Por medio de la cual se incorporan algunas modificaciones al capítulo décimo segundo del título primero de la circular básica jurídica, en materia de requerimientos mínimos de seguridad y calidad para la realización de operaciones. 4 de octubre de 2012; Superintendencia Financiera de Colombia. Circular Externa 038 de 2011. Sobre información a los consumidores financieros. 6 de septiembre de 2011; Superintendencia Financiera de Colombia. Circular Externa 039 de 2011. Sobre cláusulas y prácticas abusivas. 6 de septiembre de 2011 . 
de crédito, las tarjetas inteligentes ${ }^{4}$, así como los mecanismos de transferencia electrónica de fondos 5 .

A partir de lo anterior, se entiende en el presente escrito el "fraude electrónico" como la conducta desplegada por un tercero ajeno al titular del medio electrónico de pago, no autorizada ni consentida por este, por conductos electrónicos y que le causa un perjuicio.

Siguiendo a Mariño López, podemos definir el "fraude electrónico" como el escenario en el que "un tercero se apropia de los datos de identificación de la tarjeta de crédito [o de cualquier medio electrónico de pago individual] y de su titular y, empleando los mismos, celebra contratos a distancia por medios electrónicos, telefónicos o telemáticos" $"$, debiendo aclarar que más bien utiliza dichos datos para efectuar el pago de las obligaciones derivadas de dichos contratos a distancia, realiza transferencias electrónicas de dinero a cuentas previamente determinadas, o bien efectúa retiros de dinero en efectivo a través de cajeros electrónicos.

Dada la definición esbozada, es claro que no es objeto del presente análisis el fraude que sobre medios de pago electrónicos pueda generarse por virtud de acciones físicamente verificables, como por ejemplo el hurto del plástico y su posterior uso mediante presencia física del delincuente en un establecimiento de comercio o en un cajero electrónico, o la falsificación del plástico con los mismos fines.

Con base en lo expuesto, podemos identificar al menos las siguientes situaciones de las que podría generarse un fraude electrónico:

4 Héctor García Santiago, óp. cit., 194.

5 Leandro Emilio Toscano, El derecho bancario frente a las nuevas tecnologías. Los riesgos derivados de su aplicación, 33 Enfoque integral y práctico de la cuestión. Disponible en: www. derechoybanca.com (Recuperado el $1^{\circ}$ de diciembre de 2007).

6 Andrés Mariño López, Responsabilidad Contractual por utilización indebida de tarjeta de crédito, tesis doctoral, Universidad Autónoma de Barcelona, Barcelona, 134 (2003). 
a. Interceptación de los datos propios del medio de pago electrónico y su titular a través de los canales electrónicos por los cuales circula la información ${ }^{7}$, v. gr. en la internet ${ }^{8}$.

b. Consecución de los datos propios del medio de pago electrónico y su titular a través de la extracción de la información de las bandas magnéticas de las tarjetas débito o de crédito, o del chip de la tarjeta inteligente, mediante la incorporación de mecanismos simulados en cajeros electrónicos y datáfonos.

Como puede advertirse, dichas situaciones no comprometen, en términos generales, la debida diligencia que debe emplear el cliente o titular del medio electrónico de pago, en otros términos, el fraude electrónico, según lo expuesto, puede tener lugar al margen de una extrema diligencia en la custodia de los medios de pago por parte de su titular.

7 "La experiencia indica, igualmente que las contraseñas y palabras clave (PIN) han dejado de ser un mecanismo suficientemente fiable y seguro, ya que estas pueden ser interceptadas durante su transmisión y han demostrado reiteradamente su alto grado de vulnerabilidad, lo que ha obligado a extremar los recaudos en la materia, como por ejemplo:

“- Ataques a la confidencialidad de la información: Ingreso de intrusos entre el origen y destino de la información transmitida.

“- Ataques a la integridad de la información: Modificación de la información trasmitida.

“- Acceso a la información por parte de personas no autorizadas: Entrada a aplicaciones o sistemas mediante la sustracción del login y password de una persona autorizada.

"• Ataques a la disponibilidad de los sistemas: Acciones externas que tienen como origen bloquear un sistema”. Horacio Roberto Granero, Aspectos legales y prácticos de la implementación de una infraestructura bancaria de firma digital, 2. Disponible en: www.derechoybanca.com (recuperado el $1^{\circ}$ de diciembre de 2007).

8 Esta problemática podría solucionarse, en gran medida, a través de la utilización del mecanismo de firma digital por parte de los titulares de los medios electrónicos de pago, pues de esta manera la información viajaría encriptada a través de los canales informáticos, lo que imposibilitaría o al menos dificultaría su interceptación y, principalmente, su utilización indebida. Sin embargo, como lo anota Mariño López, "Si bien la utilización de mecanismos de firma digital (criptografía asimétrica) elimina el problema de inseguridad de los pagos por medio de tarjeta de crédito en Internet y determina el desarrollo y consolidación de este instrumento de pago en el ámbito de la contratación telemática la cual presentaría una forma eficaz y segura de cumplimiento de las obligaciones dinerarias realizadas en dicha área, los costes de la tecnología de certificación digital no permiten todavía su difusión masiva en el ámbito de los usuarios de tarjeta de crédito. En su desarrollo actual, la firma digital es utilizada principalmente para los contratos electrónicos celebrados entre empresas pero ello no significa que en un futuro no pueda ser utilizada en forma masiva por consumidores. El mecanismo para dotar de seguridad a los pagos por medio de tarjeta de crédito en los contratos celebrados por medios telemáticos y electrónicos ya existe, solo resta su difusión que se alcanzará una vez obtenido un coste razonable para la tecnología a utilizar”. Andrés Mariño López, óp. cit., 164. 


\section{A. Régimen tradicional: responsabilidad subjetiva}

El régimen de responsabilidad subjetiva se basa o tiene su fundamento en la noción de "culpa", es decir, en la intención de inferir daño por parte de su causante, o el grado de impericia o de negligencia que genera tal daño.

Así, el mecanismo principal para determinar la ausencia de responsabilidad por parte del causante del daño es la demostración de la diligencia que le es exigida en el caso particular ${ }^{9}$.

Ahora bien, como estamos frente a una responsabilidad contractual, es menester concluir que de conformidad con el artículo 1604 del Código Civil, fundamento de este régimen en nuestro país, sería la entidad emisora del medio de pago quien estaría en la obligación de probar que actuó en forma diligente, por lo que al titular de dicho medio de pago solo le incumbe afirmar que sus perjuicios derivaron del incumplimiento contractual de parte de la entidad financiera; en otros términos, teniendo en cuenta que la responsabilidad contractual parte de presumir la culpa, se invierte la carga de la prueba y entonces no corresponde al titular del medio de pago probarla, sino al emisor acreditar su diligencia. Teniendo en cuenta, además, que la entidad financiera es un profesional en el desarrollo de su actividad, no está de más indicar que le corresponde un grado máximo de diligencia, por lo que responderá incluso de culpa levísima ${ }^{10}$.

9 Dentro de nuestro régimen jurídico, la culpa se gradúa bajo tres hipótesis, la culpa grave, que se equipara al dolo o la intención de inferir el daño y que consiste en la falta de diligencia aún de las personas de poca prudencia, la culpa leve, que corresponde a la falta de diligencia de un padre de familia y la culpa levísima, inherente a la falta de diligencia de un buen hombre de negocios. Cfr. Código Civil [C.C.]. Ley 57 de 1887. Artículo 63 (Colombia).

10 Si bien el artículo 1604 del Código Civil refiere que el deudor solo responde de culpa levísima en los casos en los que el contrato solo le reporta a este beneficio, lo que llevaría a concluir que la entidad emisora del medio de pago responde hasta por culpa leve, no debe dejarse de lado que los contratos derivados o cuya fuente la constituye el ejercicio de la actividad financiera tienen una connotación particular, por tratarse de un servicio público, de interés general y desarrollado por profesionales en la materia, es decir, por entidades que deben emplear la diligencia de un buen hombre de negocios en sus actuaciones. No así ha de ocurrir con el cliente o titular del medio electrónico de pago, pues por más que consideremos que es un comerciante y profesional en su actividad, no desarrolla la actividad financiera y, en todo caso, no le es exigible el grado máximo de diligencia en desarrollo del contrato celebrado con la entidad bancaria. Por tal razón, su responsabilidad contractual se reduce hasta la culpa leve. Adicionalmente, es de considerar que por virtud de algunas cláusulas contractuales, se modifica la responsabilidad del cliente hasta la culpa levísima, lo que aunado al hecho que se trata de contratos de adhesión y con servicios con demanda que tiende a la perfecta inelasticidad, lleva a concluir que se trata de cláusulas abusivas que carecerían de efectos. 
Sin embargo, teniendo como presupuesto el hecho de que la única fuente normativa de la relación jurídica entre el titular del medio de pago y su emisor es el contrato, que además es en la mayoría de los casos de adhesión, no es del todo sencillo acreditar que una de las obligaciones de la entidad financiera es brindar a sus clientes completa seguridad en la utilización de los medios electrónicos de pago $^{11}$. De la misma manera, se debe partir del supuesto de que por tratarse de responsabilidad subjetiva, la entidad bancaria está obligada a desarrollar sus actividades tendientes a brindar seguridad en transacciones electrónicas con el mayor grado de diligencia, pero no puede garantizar un resultado, pues trascendería entonces su obligación al ámbito de la responsabilidad objetiva.

Todo lo expuesto permite concluir que, bajo los supuestos planteados que como ya se indicó no comprometen la diligencia del titular del medio de pago en su custodia, basta su manifestación en torno al incumplimiento contractual por parte de la entidad bancaria que derivó en el fraude electrónico, acreditando la causación y el monto de los perjuicios, para que surja la responsabilidad civil como fuente de la obligación a cargo de la entidad bancaria de indemnizar los perjuicios, la que solo resultará indemne si acredita el mayor grado de diligencia.

Sin embargo, existe un evento que podría llegar a desvirtuar con argumentos prácticos lo hasta acá expuesto, que se circunscribe al pacto contractual según el cual toda transacción u operación electrónica efectuada con el medio electrónico de pago y la contraseña entregada a su titular, se entiende realizada por este.

Es evidente que en esta hipótesis, por más pacto contractual que exista en torno a la obligación del emisor del medio de pago de brindar herramientas de seguridad a los clientes, bien sea de manera expresa o considerándolo como un elemento natural del contrato, basta para la entidad financiera indicar que la operación fue exitosa, pues se realizó con el medio de pago y su contraseña, que es el principal medio de seguridad brindado por el banco. Así, ni siquiera cabe considerar un incumplimiento contractual del emi-

11 Toscano considera como una cláusula natural de la relación entre el banco emisor y el titular de los medios electrónicos de pago la obligación de brindar seguridad a cargo de la entidad financiera. Por tal razón, no sería menester acreditar por parte del cliente perjudicado dicha circunstancia, sino que más bien incumbiría al banco probar que mediante una cláusula accidental se pactó en contrario. Cfr. Leandro Emilio Toscano, óp. cit., 9. 
sor, que permitiera la argumentación bajo la culpa presunta, pues el banco estaría cumpliendo a cabalidad lo pactado.

Más adelante abordaremos nuevamente este escenario, pero bajo el régimen de responsabilidad objetiva.

\section{B. Planteamiento bajo el régimen de responsabilidad objetiva}

La responsabilidad objetiva surgió dentro de la evolución del régimen de responsabilidad subjetiva, principalmente para equilibrar las cargas probatorias ante algunas situaciones que resultaban ser a todas luces inequitativas.

El planteamiento hecho bajo el régimen de responsabilidad objetiva parte de un supuesto completamente distinto al indicado en el acápite anterior, pues en este caso si bien la responsabilidad continúa siendo contractual, ahora la entidad financiera no se exime de responsabilidad probando simplemente la máxima diligencia en la gestión de la seguridad informática, sino que debe garantizar un resultado.

Sin embargo, la posibilidad de obligar a las entidades financieras al pago de la indemnización derivada de los fraudes electrónicos al tenor de la responsabilidad objetiva se ha cimentado en las teorías del riesgo, que se han estructurado ya no bajo la órbita de la responsabilidad contractual, sino de la extracontractual, es decir, no se parte de la existencia de una relación contractual y el incumplimiento de las obligaciones a cargo de la entidad financiera, sino del riesgo originado en la actividad desplegada por el emisor de los medios electrónicos de pago, por lo que, bajo ese supuesto, deberá indemnizar perjuicios que se causen incluso a quienes no tienen ningún tipo de relación jurídica con este. Debe entenderse el riesgo como la probabilidad de ocurrencia de una situación que genere un perjuicio de orden patrimonial a quien lo genera o a un tercero.

La teoría de la responsabilidad objetiva con fundamento en los riesgos surgió en Francia a partir del inciso primero del artículo 
1384 del Código Civil'12, según el cual13 "Se es responsable no solo del daño causado por sus propios actos, sino también de aquellos causados por los hechos de las personas por las cuales debe responderse, o de las cosas sobre las cuales se tiene bajo su guarda"14. Disposición similar se encuentra en otras codificaciones ${ }^{15}$, situación que no ocurre en el caso colombiano y permitiría llegar a la conclusión, al menos en principio, de que esta no es aplicable en el ordenamiento jurídico vernáculo ${ }^{16}$.

La teoría del riesgo tiene tres vertientes principales, como se indica a continuación.

En primer lugar, en el escenario del riesgo creado, quien en desarrollo de una actividad genere un riesgo, está en la obligación de indemnizar los perjuicios que de este devengan sobre terceros. Aquí no entra en consideración si el agente que genera el riesgo

12 Sobre la evolución histórica y las discusiones doctrinales y jurisprudenciales en torno a la aplicación del inciso primero del artículo 1384 del Código Civil francés en desarrollo de la responsabilidad objetiva bajo la teoría del riesgo, cfr. Manuel Guillermo Sarmiento García, La teoría del riesgo y la responsabilidad civil, en Estudios de responsabilidad civil, 203-224, Universidad Externado de Colombia, Bogotá D.C. (2003). Sobre la aplicación del inciso primero del artículo 1384 del Código Civil Francés y la responsabilidad por actividades peligrosas bajo el régimen colombiano, Cfr. Francisco Ternera Barrios \& Fabricio Mantilla Espinosa, La responsabilité objective du fati [sic] des activités dangereuses, Revista Estudios Socio-Jurídicos, Universidad del Rosario, Bogotá D.C., 386-405 (julio-diciembre de 2004).

13 El 29 de junio de 2007, la Corte de Casación Francesa, en reunión plenaria, profirió una sentencia bastante importante en torno al inciso primero del artículo 1384 del Código Civil, no obstante que en este caso no se trató la responsabilidad por el hecho de las cosas bajo su guarda, sino de las personas, lo que en todo caso marca un buen parámetro de análisis en torno a la responsabilidad objetiva. Cfr. Cour de Cassation, Assemblée Plénière, Arrêt No. 559 du 29 juin 2007. Disponible en: www.courdecassation.fr (Recuperado el $1^{\circ}$ de diciembre de 2007).

14 Dice el citado artículo: "On est responsable non seulement du dommage que l'on cause par son propre fait, mais encore de celui qui est causé par le fait des personnes dont on doit répondre, ou des choses que l'on a sous sa garde" (Traducción propia).

15 Por ejemplo, el artículo 1113 del Código Civil Argentino es del siguiente tenor:

"Art. 1113.- La obligación del que ha causado un daño se extiende a los daños que causaren los que están bajo su dependencia, o por las cosas de que se sirve, o que tiene a su cuidado.

“(Párrafo agregado por la Ley 17.711) En los supuestos de daños causados con las cosas, el dueño o guardián, para eximirse de responsabilidad, deberá demostrar que de su parte no hubo culpa; pero si el daño hubiere sido causado por el riesgo o vicio de la cosa, solo se eximirá total o parcialmente de responsabilidad acreditando la culpa de la víctima o de un tercero por quien no debe responder.

"Si la cosa hubiese sido usada contra la voluntad expresa o presunta del dueño o guardián, no será responsable” (resaltado fuera del texto). Código Civil [C.C.]. Ley 340 de septiembre 25 de 1869 (Argentina).

16 El profesor Sarmiento García es partidario de la tesis según la cual no obstante la inexistencia de una regulación expresa sobre el particular, la responsabilidad objetiva es plenamente aplicable en el caso colombiano a partir de las disposiciones del Código Civil. Cfr. Manuel Guillermo Sarmiento García, óp. cit., 224-242. 
obtiene o no provecho alguno con la actividad, sino simplemente si esta crea un riesgo.

En segundo lugar, bajo la teoría del riesgo provecho, quien ejerza una actividad que genere un riesgo y obtenga de esta una utilidad, un provecho ${ }^{17}$, deberá indemnizar los perjuicios que se causen y que sean derivados de tal riesgo, sin importar si obró o no en forma diligente ${ }^{18}$.

Finalmente, el riesgo profesional se ha considerado por la doctrina como una vertiente del riesgo provecho, de donde devino el desarrollo de la responsabilidad por accidentes de trabajo ${ }^{19}$. No obstante lo anterior, se ha intentado darle un desarrollo independiente, considerando el riesgo derivado de las actividades que requieren un cierto grado de profesionalismo, como podría ocurrir con las

17 Como lo anota el profesor chileno Juan Andrés Orrego Acuña, la responsabilidad objetiva sigue, entre otros, el principio del interés activo, según el cual "las pérdidas que pueden provenir de una empresa, incluyendo en estas las indemnizaciones por los daños a terceros, son de cargo de aquel que obtiene beneficios de la misma empresa. Como señala Victor Mataja, las pérdidas y los daños provenientes de los accidentes inevitables ligados a la explotación de una empresa cualquiera, deben ser considerados, según la justa apreciación social, entre los costos de explotación de la misma". Sin embargo, conviene precisar que precisamente dentro de la administración por riesgos, tan importante en materia financiera, es importante no solo la consideración del riesgo sino su cuantificación, circunstancia particular que genera desincentivos económicos al desarrollo de la actividad económica, como se analizará más adelante. Cfr. Juan Andrés Orrego Acuña, Apuntes de responsabilidad objetiva, 6. Disponible en: www.juanandresorrego. $\mathrm{cl}$ (recuperado el 5 de diciembre de 2007).

18 De la lectura de los planteamientos del profesor García Santiago parecería sugerirse que la indemnización, bajo la teoría del riesgo provecho, ha de ser directamente proporcional al provecho obtenido con el desarrollo de la actividad riesgosa. Sin embargo, esta no parecería ser una conclusión acorde con los planteamientos de la teoría, pues si bien esta sostiene, como lo indica el profesor Sarmiento García, que "la obligación de indemnizar está en relación directa con el provecho o beneficio que una determinada actividad le represente al autor del daño [...]", ello no significa cosa distinta a que debe existir un nexo de causalidad entre la actividad generadora del riesgo y el daño causado, pero en ninguna medida el daño puede ser fuente de enriquecimiento para quien soporta el perjuicio, en el evento en que la relación del provecho con el daño sea superior al perjuicio efectivamente causado, ni viceversa. Debe recordarse que la indemnización es integral y busca colocar al perjudicado en condiciones equivalentes a las que se encontraba antes del suceso calamitoso. Cfr. Héctor García Santiago, óp. cit., 214; Manuel Guillermo Sarmiento García, óp. cit., 183. Sobre el análisis económico de estas posibilidades indemnizatorias, Cfr. Mitchell Polinsky \& Steven Shavell, Should liability be based on the harm to the victim or the gain to the injurer?, National Bureau of Economic Research - Nber, Nber Working Paper Series, Working Paper No. 4586, Cambridge (1993).

19 Parece pacífica la conclusión según la cual la responsabilidad por accidentes de trabajo no solo es objetiva, sino que se fundamenta en la teoría del riesgo profesional, precisamente de ahí su nombre. Varias de las providencias de la Corte Suprema de Justicia y la Corte Constitucional evidencian la aplicación de tal teoría para los riesgos derivados de accidentes de trabajo. Cfr. v. gr. Corte Suprema de Justicia, Sala de Casación Laboral, radicación 20186. M.P. Luis Javier Osorio López, agosto 8 de 2003; Corte Constitucional, Sentencia C-453 de 2002. M.P. Álvaro Tafur Galvis, junio 12 de 2002; Corte Constitucional, Sentencia T-556 de 2003. M.P. Clara Inés Vargas Hernández, julio 3 de 2003. 
profesiones liberales, en especial la responsabilidad médica, y otras como la actividad financiera ${ }^{20}$.

Como ya hemos indicado, la máxima diligencia debida corresponde al régimen de responsabilidad subjetiva. De ahí que no compartamos los planteamientos del profesor García Santiago cuando indica que bajo las teorías del riesgo provecho, del riesgo profesional y del riesgo creado, todas correspondientes a la responsabilidad objetiva, deba exigírsele un grado sumo de diligencia a la entidad emisora de los medios electrónicos de pago, pues, se reitera, aquí ya no cabe el análisis sobre la diligencia ${ }^{21}$.

De la misma forma, cabe indicar que el hecho de que el régimen de responsabilidad sea objetivo no implica que no existan causales que eximan de responsabilidad a la entidad emisora del medio electrónico de pago, en lo absoluto. Podría considerarse como la principal la fuerza mayor o caso fortuito ${ }^{22}$, que bajo nuestro ordenamiento jurídico se nutre de dos elementos: i) la imprevisibilidad y ii) la irresistibilidad ${ }^{23}$. Cabría preguntarse si no obstante acoger la responsabilidad objetiva y extracontractual bajo la teoría del riesgo, el emisor del medio de pago pueda alegar el hecho de que no era previsible, dado el grado de sofisticación en las herramientas de seguridad implantadas, el acaecimiento de un fraude electrónico y que, además, no era resistible por las propias características en que se presentó. Consideramos que este sería un buen argumento de defensa, pero debe estar debidamente sustentado en pruebas periciales que acrediten los dos elementos atrás considerados. Este

20 Manuel Guillermo Sarmiento García, óp. cit., 183-186.

21 "Como primera medida, entonces, es importante partir de la base de la profesionalidad que cubre a la actividad bancaria. Por tanto el conjunto de obligaciones, funciones, cargas y deberes de estas implican un mayor grado de cuidado, teniendo en cuenta su posición fuerte en la relación contractual con sus clientes usuarios o consumidores, lo cual se materializa a través de los llamados contratos de adhesión. Así, el especial conocimiento del servicio que suministran implica una mayor diligencia en la prestación del mismo" (resaltado fuera del texto). Héctor García Santiago, óp. cit., 237.

"De conformidad con lo anterior, se precisa reiterar que esa condición de profesionalidad implica un grado de responsabilidad mayor, en cuanto a las seguridades e información. De suerte que la entidad debe emplear el mayor grado de diligencia y, valga decir, de profesionalismo, en la implementación de medidas de seguridad, así como frente a la información referente a riesgos y recomendaciones de seguridad" (resaltado fuera del texto). Ibídem, 239.

22 Sobre el caso fortuito y la fuerza mayor como causales eximentes de responsabilidad, bajo el régimen de la teoría de los riesgos, Cfr. Consejo de Estado, Sala de lo Contencioso Administrativo, Sección Tercera. Radicación 13477 (C.P. María Elena Giraldo Gómez. 2 de mayo de 2002).

23 Código Civil [C.C.]. Ley 57 de 1887, Artículo 64 (Colombia). 
escenario podría ser, en la práctica, idéntico al de responsabilidad contractual de culpa presunta, bajo el régimen propio de las entidades financieras, esto es, el de responsabilidad hasta culpa levísima.

Como puede advertirse, el límite entre el régimen de responsabilidad contractual bajo la culpa presunta descrita en el artículo 1604 del Código Civil y el régimen de responsabilidad extracontractual, objetivo y bajo la teoría del riesgo, es difuso. Sin embargo, es claro que en ambos casos la carga de la prueba recae en la entidad financiera, y que, en cierta medida, eximirse de responsabilidad por un grado de diligencia extremo, en el caso de la responsabilidad contractual, o por fuerza mayor, en este o en el régimen de responsabilidad extracontractual bajo la teoría del riesgo, no obstante ser dogmáticamente figuras distintas, podrían nutrirse de los mismos elementos técnicos.

Empero, bajo la hipótesis indicada en el acápite anterior en torno a las operaciones realizadas con el medio de pago y la contraseña del titular, cabe indicar aquí que por tratarse de un régimen de responsabilidad que no se encuentra fundado en el incumplimiento contractual ni mucho menos en los términos pactados por el emisor y el titular del medio electrónico de pago, consideramos que no impactaría en ninguna medida el hecho de haberse estipulado que cualquiera de estas transacciones se entienden realizadas por el titular del medio de pago, en otros términos, el régimen de responsabilidad desborda lo pactado, deja de lado la diligencia de la entidad financiera y permite estructurar su responsabilidad incluso en los eventos en que, como se está analizando, la operación se realizó con el medio electrónico de pago y la contraseña dada a su titular.

Como ya se ha expresado, ello no significa que la entidad financiera no tenga ningún mecanismo para enervar su responsabilidad, pues puede hacerlo acreditando la fuerza mayor, en los términos expuestos, la culpa exclusiva del perjudicado ${ }^{24}$, o el hecho de un tercero causante del perjuicio, es decir, rompiendo el nexo causal.

24 El profesor García Santiago refiere esta figura para el caso que nos ocupa, indicando que la entidad financiera deberá probar, para eximirse de responsabilidad, "(1) que el titular actuó de manera fraudulenta", que equivaldría a indicar que lo hizo con dolo, "(2) que el titular actuó con negligencia", o finalmente que el cliente después de las advertencias del banco, decidió asumir los riesgos. Cfr. Héctor García Santiago, óp. cit., 241. 


\section{ANÁLISIS ECONÓMICO DE LA REGLA DE RESPONSABILIDAD OBJETIVA}

El análisis económico de las normas jurídicas parte de la premisa de considerar que, como lo indica Posner, "los individuos se comportan como maximizadores racionales de su bienestar cuando realizan decisiones no relacionadas [directamente] con alguna actividad de mercado" 25 , lo que requiere una eficiente asignación de los recursos a su disposición.

De la misma forma, siguiendo a Kitch, "las leyes que rigen los derechos de propiedad, la obligatoriedad de los contratos y la libertad de la actividad comercial desempeñan un papel importante en la manera como se comportan los mercados. Así, un interés en el comportamiento del mercado conduce naturalmente a un interés en el derecho y en la manera en que este afecta la conducta de aquel"26.

Sin embargo, muchas de las reglas de derecho, que no deben analizarse bajo otro supuesto distinto al de tenerlas como incentivos ${ }^{27}$, no permiten lograr el mayor grado de eficiencia y, de contera, no se consigue maximizar el bienestar de los agentes, generando en la misma medida efectos en los mercados que no siempre son los más deseados.

Con base en lo someramente expuesto, el propósito de este acápite es analizar, bajo las reglas económicas que propenden por la eficiente asignación de los recursos y la maximización del bienestar de los agentes, la responsabilidad de las entidades emisoras de los medios de pago bajo la regla objetiva, extracontractual y basada en la teoría del riesgo, esbozada en el capítulo anterior, y exponer en forma sucinta la consecuencia que podría presentarse en el mercado financiero.

25 Richard Posner, El movimiento del análisis económico del derecho, en Derecho y economía: una revisión de la literatura, 227, Fondo de Cultura Económica, México D.F. (2000).

26 Edmund Kitch, Los fundamentos intelectuales del análisis económico del derecho, en Derecho y economía: una revisión de la literatura, 51, Fondo de Cultura Económica, México D.F. (2000).

27 Lewis Kornhauser, El nuevo análisis económico del derecho: las normas jurídicas como incentivos, en Derecho y economía: una revisión de la literatura, 19-50, Fondo de Cultura Económica, México D.F. (2000). 


\section{A. E1 mercado financiero colombiano}

Como se señaló anteriormente, el mercado financiero colombiano es un mercado oligopólico que compite en precios, es decir, cuyos presupuestos económicos se cimentan en el modelo construido por Bertrand ${ }^{28}$. Si bien existen, al corte de abril de 2013, sesenta y nueve entidades vigiladas por la Superintendencia Financiera de Colombia autorizadas para captar ahorros del público ${ }^{29}$, tan solo veintitrés de ellas, que operan como establecimientos bancarios, representan el $86,17 \%$ de la cartera de créditos y el $87,74 \%$ de los depósitos del sistema financiero. A su vez, apenas cinco establecimientos bancarios (Bancolombia, Banco de Bogotá, Davivienda, BBVA, y Banco de Occidente) representan en conjunto más de la mitad de todo el sistema financiero colombiano $(57,21 \%$ del total de la cartera y 56,27\% del total de los depósitos).

Ahora bien, si consideramos el Índice de Concentración de Hirschman y Herfindahl ( $\mathrm{IHH})^{30}$, a partir de las cifras reportadas por la Superintendencia Financiera de Colombia por las entidades financieras autorizadas para operar en nuestro país, al corte del mes de abril de 2013, tales cinco entidades (Bancolombia, Banco de Bogotá, Davivienda, BBva, y Banco de Occidente) alcanzarían un índice de 3.272,8 en cartera y de 3.166 en depósitos, es decir, se evidenciaría una clara concentración. Si bien ello podría dar para concluir que el modelo oligopólico no sería el de Bertrand, para llegar a tal conclusión se requeriría que se acreditara que las entidades

28 Para mayor profundidad en el análisis de los modelos oligopólicos del mercado financiero, Cfr., Ricardo Bernal Fandiño, Concentración y competencia en el sistema financiero crediticio colombiano en la última década, Banco de la República, Borradores de economía, No. 432, Bogotá D.C. (2007).

29 Veintitrés establecimientos bancarios, cinco corporaciones financieras, veintidós compañías de financiamiento, un organismo cooperativo de grado superior de carácter financiero, once instituciones oficiales especiales y seis cooperativas financieras. No se tuvieron en cuenta las cooperativas de ahorro y crédito, ni las multi-activas o integrales con sección de ahorro y crédito, vigiladas por la Superintendencia de la Economía Solidaria, pues no obstante estar autorizadas para captar ahorros de sus propios asociados, no representan una participación significativa dentro del mercado financiero colombiano.

30 "El índice fue desarrollado independientemente por los economistas A. O. Hirschman (en 1945) y O. C. Herfindahl (en 1950). Hirschman presentó el índice en su libro National Power and the Structure of Foreign Trade (Berkeley: University of California Press, 1945). El indice de Herfindahl fue presentado en su tesis doctoral no publicada, "Concentration in the U.S. Steel Industry" (Columbia University, 1950)". Tomado de Stephen Rhoades, The Herfindahl-Hirschman Index, 79 Federal Reserve Bulletin, 188 (march 1993, traducción propia). El índice corresponde a $I H H=\sum_{i=1}^{n} S_{i}^{2}$, es decir, a la sumatoria de la participación de cada firma al cuadrado. 
anteriormente citadas actúan como un solo agente y que existiera un acuerdo colusorio entre ellas, expreso o tácito, circunstancias que no han sido declaradas por las autoridades competentes.

De otro lado, es importante tener en cuenta que la función objetivo de la entidad financiera, como oferente de servicios financieros electrónicos, es maximizar sus utilidades y la valoración de su empresa, con sujeción a la restricción tecnológica. Dada la profesionalidad de este agente, las normas que regulan su actividad exigen estructurar esquemas de administración basados en el riesgo, donde el riesgo operativo juega un papel preponderante en materia de fraude electrónico ${ }^{31}$. Así, teniendo en cuenta que los diversos riesgos que implica el ejercicio de la actividad financiera son plenamente asumidos cuando la entidad opta por dedicarse a esta, no podríamos concluir cosa distinta a que se trata de un agente propenso a la asunción de riesgos, o cuando menos, que no se trata de un agente adverso o neutral al riesgo.

Para los propósitos del presente análisis, entiéndase por riesgo la probabilidad de merma, disminución o perjuicio patrimonial, derivado de un hecho futuro e incierto, como consecuencia de la conducta de un tercero.

Entre tanto, para el titular del medio electrónico de pago la función objetivo será la maximización de su bienestar, sujeto a la restricción de la riqueza. De ahí que podamos concluir que un riesgo de fraude pondría al consumidor financiero en el siguiente escenario:

$$
V E_{w}=w_{S F}(1-q)+w_{C F} q
$$

En la anterior ecuación, $\mathrm{VE}_{\mathrm{w}}$ es el valor esperado del patrimonio, $\mathrm{w}_{\mathrm{SF}}$ es el valor del patrimonio en el evento en que no haya fraude, $\mathrm{w}_{\mathrm{CF}}$ es el valor del patrimonio en el evento en que haya fraude y la probabilidad de ocurrencia del fraude, es decir, solo planteamos dos escenarios: hay fraude, o no hay fraude. $\mathrm{Si}$ expresamos $\mathrm{w}_{\mathrm{SF}}$ como $\mathrm{w}_{1}$ con su probabilidad $\pi_{1} \mathrm{y} \mathrm{w}_{\mathrm{CF}}$ como $\mathrm{w}_{2}$ con su probabilidad $\pi_{2}$, tal valor esperado lo podemos expresar igualmente como:

$$
V E_{w}=w_{1} \pi_{1}+w_{2} \pi_{2}
$$

En este caso, evidentemente partimos del supuesto de que no existe ningún tipo de riesgo moral, es decir, que el fraude se genera por circunstancias completamente exógenas al consumidor

31 Superintendencia Financiera de Colombia. Circular Básica Contable y Financiera, Capítulo XXIII. 
financiero, incluso ajenas a su propia negligencia, tal como quedó anotado anteriormente ${ }^{32}$.

Teniendo en cuenta lo anterior, el consumidor financiero tendrá una función de utilidad (u) de Von Neumann Morgenstern ${ }^{33}$ en los siguientes términos:

$$
u=f\left(w_{0}, w_{1}, w_{2}, \pi_{1}, \pi_{2}\right)
$$

Acá incluimos $\mathrm{w}_{0}$ que corresponde al valor actual del patrimonio, es decir, el valor de dicho patrimonio en el momento en que se aborda el análisis de la situación futura de incertidumbre.

Los agentes económicos involucrados en la hipótesis planteada son principalmente la entidad financiera como emisor del medio electrónico de pago, y el cliente como titular del mismo. No obstante lo anterior, es importante tener en cuenta, aunque no en la misma medida, los establecimientos de comercio afiliados a la red de pagos electrónicos del emisor del medio de pago, cuando a ello haya lugar.

De otro lado, desde el punto de vista de la demanda, los servicios financieros (activos, pasivos y neutros) son preponderantemente inelásticos especialmente en los casos en que los consumidores financieros son personas con un nivel estándar o bajo de alfabetización financiera, es decir, no son sensibles a una variación en el precio, que para el caso de las operaciones activas y pasivas no es otro que la tasa de interés ${ }^{34}$.

Bajo el panorama anteriormente descrito, ¿cuál será el régimen de responsabilidad más eficiente, en materia de fraudes electrónicos?

\section{B. Fallas del mercado}

Bajo un concepto bastante sencillo, podemos definir las fallas del mercado como aquellas situaciones en las que no existe una eficiente asignación de recursos ${ }^{35}$.

\footnotetext{
32 Vid. Supra. Núm. 2.

33 Hal Varian, Microeconomía intermedia, $8^{\mathrm{a}}$ ed., Antoni Bosch, Barcelona, 228 (2010).

34 Cfr., entre otros, Asociación Nacional de Instituciones Financieras - ANIF, Informe Semanal No. 1065 del 22 de marzo de 2011. Disponible en: www.anif.co; Confederación Colombiana de Cooperativas - Confecoop, Observatorio Cooperativo No. 12, Las tasas de interés en el sector cooperativo colombiano (diciembre de 2010). Disponible en: www.confecoop.coop. En contrario, para el caso ecuatoriano, Superintendencia de Bancos y Seguros del Ecuador, Dirección Nacional de Estudios, Subdirección de Estudios, Sistema Financiero Sensibilidad de la Demanda por Créditos - Tasa de Interés, período diciembre de 2010 - diciembre de 2011. Disponible en: www.sbs.gob.ec.

35 Gregory Mankiw, Principios de economía, $3^{\mathrm{a}}$ ed., McGraw Hill, Madrid, 7 (2004).
} 
Para determinar la eficiencia, tendremos en cuenta el criterio de Pareto según el cual un escenario es eficiente si no existe la posibilidad de mejorar un agente sin empeorar a otro. Adicionalmente, cobrará bastante importancia en este estudio el criterio de KaldorHicks, según el cual el escenario será eficiente si el beneficio que obtiene un agente, con disposición de pago, es de tal magnitud que le permite compensar hipotéticamente el perjuicio causado a los demás agentes y aun así obtener un provecho ${ }^{36}$.

Con base en lo anterior, podríamos considerar como las principales fallas del mercado, que afectan el asunto objeto de análisis, el problema de selección adversa y el riesgo moral, derivados ambos de la asimetría de la información.

La asimetría de la información es la falla del mercado que se presenta en aquellos eventos en los que la información con que cuentan los agentes no es suficiente para la toma de una decisión que maximice en la mayor medida posible su bienestar, en torno a los productos o servicios a adquirir, o en torno a los demás agentes implicados en la operación.

Para el caso que nos ocupa, esto es, la responsabilidad objetiva de los emisores de los medios de pago con base en la teoría del riesgo, la asimetría de la información se presenta principalmente para el caso de los titulares de los medios de pago, en torno a la seguridad informática que le brinda el emisor del medio de pago, lo que puede generar problemas de selección adversa, mientras que para los emisores de los medios de pago con respecto al comportamiento de los titulares de los medios de pago, lo que conlleva el problema del riesgo moral.

\section{Selección adversa}

Para el caso de los titulares de los medios de pago, la selección adversa se presenta en la medida en que la decisión de contratar o no con determinada entidad financiera la emisión de un medio electrónico de pago depende de características no observables del otro agente, esto es, de la entidad financiera, en torno a la seguridad que esta brinda a sus clientes para prevenir el fraude electrónico.

36 Carlos Pablo Márquez Escobar, Anotaciones sobre análisis económico del derecho, vol. I, Pontificia Universidad Javeriana, Bogotá D.C., 171 (2005). 
Así, la decisión puede estar afectada al no ser la más eficiente para cumplir su función objetivo ${ }^{37}$.

Sin embargo, al establecerse un régimen de responsabilidad objetiva como el propuesto, el problema de selección adversa ya no tendrá en cuenta únicamente la seguridad informática, sino también la posibilidad de pago indemnizatorio por parte de la entidad bancaria al cliente perjudicado, pues al cargarse todo el riesgo de fraude electrónico al emisor del medio de pago aumenta su costo de operación y, eventualmente, no podrá soportarlo.

Empero, la selección adversa no parece ser un problema con la importancia necesaria para profundizar en su análisis, como sí ocurre con el riesgo moral.

\section{Riesgo moral}

El riesgo moral tiene lugar en el evento en que un agente debe desarrollar una conducta que genera necesariamente un impacto en otro agente, pero este último no cuenta con los mecanismos necesarios para desarrollar un monitoreo y control pleno sobre la conducta del primero, razón por la cual este no brinda todo su empeño en el cumplimiento de esa labor, o en algunos casos su voluntad tiende hacia la conducta contraria, generando perjuicios para el agente sobre el cual impacta la conducta ${ }^{38}$.

Así, el emisor de los medios electrónicos de pago no puede ejercer ningún control sobre la debida diligencia del titular, razón por la cual si se establece el régimen objetivo de responsabilidad, el cliente de la entidad financiera no tendrá ningún incentivo para desarrollar una efectiva custodia de los medios electrónicos de pago que le han sido entregados, elevando los costos de transacción para la entidad bancaria; en otros términos, como el cliente sabe que en caso de fraude electrónico el banco habrá de pagar los perjuicios

37 "La selección adversa es un problema que surge en los mercados en los que el vendedor conoce mejor que el comprador los atributos del bien que vende, por lo que el comprador corre el riesgo de que le vendan un bien de baja calidad. Es decir, la 'selección' de los bienes en venta puede ser 'adversa' desde el punto de vista del comprador desinformado”. Gregory Mankiw, óp. cit., 298.

38 El clásico ejemplo del riesgo moral, o riesgo de inmoralidad, se presenta en materia de seguros, donde una persona adversa al riesgo traslada a la aseguradora los efectos nocivos de un siniestro. Al hacerlo, pierde los incentivos para actuar de tal modo que colabore en que el referido siniestro no se cause, por lo que la entidad aseguradora incurriría en sobrecostos. Precisamente para evitar esta situación se crearon figuras como el deducible, que disminuye el riesgo moral del asegurado, al tener que asumir necesariamente un porcentaje de la pérdida. 
que le sean causados, se desinteresará en desplegar una conducta que tienda a evitar que este ocurra, pues finalmente no deberá asumir pérdida alguna.

\section{Una aproximación a la regla de Hand}

Podría pensarse que al existir causales eximentes de responsabilidad, aun bajo el régimen objetivo, especialmente el fraude por parte del mismo cliente, existe un incentivo al menos para no incurrir en esas prácticas. Sin embargo, lo cierto es que el cálculo de las probabilidades juega en contra de la entidad bancaria, pues prácticamente no existirá evento alguno en que pueda probarse el fraude por parte del cliente, o mejor, en la mayoría de los casos, el costo de probar el fraude del cliente va a ser mayor que el valor de la indemnización, razón por la cual la entidad financiera procederá al pago.

Con base en lo expuesto, es importante analizar dos tipos de costos: i) los costos de precaución, es decir, aquellos en que debe incurrir la entidad bancaria para evitar que se presenten fraudes electrónicos y que corresponderán en su totalidad a esta, pues no existen incentivos para que el titular del medio de pago sea precavido; y ii) los costos del daño esperado, correspondientes al valor de los perjuicios calculados multiplicados por la probabilidad de ocurrencia. Este es uno de los aspectos más importantes, pues bajo la regla de la responsabilidad objetiva se desconocería el monto de los perjuicios que podrían causarse, y la probabilidad de ocurrencia sería tendiente al ciento por ciento, como se expuso anteriormente.

Dado lo anterior, bajo la regla de $\mathrm{Hand}^{39}$, el titular del medio electrónico de pago será negligente, pues el beneficio marginal de su precaución es inferior que el beneficio marginal que obtiene. Sin embargo, esa negligencia no necesariamente permitirá a la entidad

39 Esta regla se debe al juez Hand, quien en la resolución del caso United States vs. Carroll Towing Co. en 1947, efectuó un análisis económico sobre la negligencia y la asignación de responsabilidad, indicando que, como se manifestó para el caso objeto de estudio, una persona es negligente si el costo de su precaución es inferior que el beneficio que obtiene. Con base en lo anterior, se determinó que existe responsabilidad si el costo de precaución es menor que el costo del perjuicio multiplicado por la probabilidad de ocurrencia, en otros términos, cuando $\mathrm{B}<\mathrm{P} * \mathrm{~L}$, donde $\mathrm{B}$ es el costo de la precaución, P la probabilidad de daño y L el monto del perjuicio. En el escenario contrario, esto es, si $\mathrm{B}>\mathrm{P} * \mathrm{~L}$, no habrá responsabilidad, pues sería una solución ineficiente. Sin embargo, dicha versión inicial no incorpora un análisis marginal, por lo que debe ajustarse indicando que habrá responsabilidad si el costo marginal de la precaución es menor que el costo marginal del perjuicio multiplicado por la probabilidad de ocurrencia. 
financiera eximirse de responsabilidad, pues los costos de probar dicha negligencia, en la mayoría de los eventos, serán superiores, como se indicó, al valor de la indemnización. Siguiendo a Hand, la entidad financiera no tendría la obligación de asumir responsabilidad teniendo en cuenta que el costo de su precaución, incluyendo los costos de transacción, es sustancialmente superior al del daño multiplicado por la probabilidad de ocurrencia, incluyendo en este caso todos los clientes de medios electrónicos de pago, en otros términos, bajo la regla que estamos estudiando se daría una asignación ineficiente de los riesgos en términos de Kaldor-Hicks ${ }^{40}$.

Como sostiene Coase, "el problema que enfrentamos al manejar acciones que tienen efectos dañinos no es sencillamente restringir a los responsables de los mismos. Lo que debe decidirse es si la ganancia por evitar el daño es mayor que la pérdida que se sufriría de otro modo, como resultado de detener la acción que produce el daño"41.

Ante tal situación, existen dos posibles acciones por parte de la entidad financiera: i) Internalizar los costos adicionales en que debe incurrir, generando un aumento en el precio de sus servicios, lo que finalmente generará una disminución en las cantidades demandadas de los medios electrónicos de pago, efecto a todas luces nocivo para el mercado financiero y la economía en general, más aún en un mercado como el colombiano con las características oligopólicas y de inelasticidad ya anotadas, y en donde además existe un límite regulado a las tasas de interés. Esta solución, además, puede resultar imposible en la práctica, pues como se indicó anteriormente, determinar el monto probable de los perjuicios a indemnizar para internalizar dichos costos no es posible en la medida en que se

40 Esta situación podía advertirse en el derogado artículo 46 de la Ley de Ordenación del Comercio Minorista de España, donde ante compras efectuadas por vías electrónicas, el titular del medio de pago tenía la posibilidad de repudio solo con la manifestación de considerar la operación como fraudulenta. En ese caso, quien asumía la carga es el establecimiento de comercio, pues el banco debía retirar los fondos de su cuenta y retornarlos a la del titular del medio de pago. El establecimiento solo se liberaba si probaba que sí efectuó la transacción con el titular y que por ende no hubo fraude. Así, como lo indica Mariño López, "la prueba [de] que el contrato se celebró con quien anula el cargo en forma indebida corresponde al establecimiento adherido, lo cual es sumamente dificil, precisamente, por el hecho de tratarse de un contrato y un pago a distancia. Por ello, cabe concluir que en los casos de uso indebido de una tarjeta de crédito en un pago realizado a distancia, el titular se exonera de responsabilidad solicitando a la entidad emisora la anulación del cargo, recayendo en el establecimiento adherido los perjuicios que dicho uso ilegítimo puede haber ocasionado”. Andrés Mariño López, óp. cit., 215.

41 Ronald Coase, El problema del costo social, en Derecho y economía: una revisión de la literatura, Fondo de Cultura Económica, México D.F., 538 (2000). 
asumen todos los riesgos. ii) Dejar de prestar ese servicio, pues le saldrá más costoso prestarlo que dejarlo de hacer ${ }^{42}$. Definitivamente los dos escenarios son perjudiciales en términos económicos.

\section{La negligencia contribuyente y la negligencia compa- rativa}

Dejando ya de lado la responsabilidad objetiva y volviendo al régimen subjetivo, conviene analizar económicamente las teorías de la negligencia contribuyente y la negligencia comparativa bajo el prisma del tema objeto de estudio, no obstante que la primera de ellas no es de recibo en el ordenamiento jurídico nacional, es decir, se trata de un ejercicio meramente académico.

La negligencia contribuyente ha sido considerada como una causal eximente de responsabilidad bajo la cual, si la víctima ha contribuido en la causación del daño, el victimario no es responsable, sin importar el modo en que su conducta ha influido en el resultado, incluso actuando con culpa grave. Algunos consideran que se trata de un régimen de responsabilidad bastante injusto y por la misma razón ha sido proscrito de la mayoría de regulaciones jurídicas, quedando apenas en algunas latitudes, entre ellas algunos estados de los Estados Unidos de América ${ }^{43}$.

Como lo anota $\mathrm{Posner}^{44}$, la regla de la negligencia contribuyente es la continuación del análisis de la responsabilidad bajo la regla de Hand, en la que se incluye el análisis de la conducta de la víctima; en otros términos, si bajo la regla de Hand el demandado resulta siendo responsable, es menester determinar la negligencia de la víctima y su incidencia en la generación del daño.

42 "Sabiendo el hombre de que debe responder de todo daño, aunque provenga de un hecho lícito e irreprochable, se abstendrá de obrar, o, en todo caso, lo hará con menor intensidad. Se castigaría así al que actuó, al que ejercitó una actividad que seguramente es útil para la sociedad, y se protegería a quien ha permanecido en la más completa pasividad. El individuo que para actuar requiere necesariamente una cierta libertad y seguridad acerca de que si se conduce bien no será requerido, dudará en desarrollar una nueva actividad, de saber que, pese a toda su prudencia, tendrá que cargar sobre sí la responsabilidad de todos los daños que puedan resultar de tal actividad”. Juan Andrés Orrego Acuña, óp. cit., 13.

43 William Mills, Contributory Negligence. Disponible en: www.ncatl.org (recuperado el 22 de enero de 2008).

44 Richard Posner, El análisis económico del derecho, $2^{\mathrm{a}}$ ed. en español, Fondo de Cultura Económica, México, D.F., 279 (2007). 
Así las cosas, es evidente que sería contrario a tal eficiencia que por cualquier tipo de negligencia del consumidor, incluso si el proveedor del servicio ha sido también negligente, este se exonerara de responsabilidad; en otros términos, haría que el banco asumiera una mayor indiferencia con la diligencia que debe asumir ${ }^{45}$. Por lo tanto, si se aplicara esa regla, definitivamente se generaría un desincentivo para que las entidades financieras tomaran la debida precaución y la seguridad necesaria en materia de transacciones electrónicas, pues con una mínima negligencia por parte del cliente bastaría para resultar completamente exentos de responsabilidad.

Por su parte, la culpa comparativa se constituye en lo que bajo nuestro ordenamiento jurídico se conoce como concurrencia de culpas, que está regulada en el artículo 2357 del Código Civil, en la que, como indica Posner, "[...] si ambas partes (el victimario y la víctima) son negligentes se reduce el pago de daños que debe recibir el demandante, pero no hasta cero" ${ }^{\prime 46}$. En otros términos, a diferencia de lo que ocurre con la culpa contribuyente en la que con cualquier negligencia de la víctima la indemnización equivale a cero, en este caso, judicialmente se pondera la contribución de la víctima en el perjuicio que a ella misma se le ha causado y disminuye en tal proporción el valor de la indemnización ${ }^{47}$.

45 Para Posner incluso la regla de la culpa contribuyente genera incentivos suficientes para que ambas partes sean diligentes. Afirma Posner: "El victimario tiene un incentivo para tomar cuidado a fin de no tener que pagar daños si es descuidado, ocurre un accidente, y la víctima no fue descuidada; la víctima tiene un incentivo para tomar cuidado a fin de evitar el costo del accidente, si ocurre a pesar de que el victimario fue cuidadoso. Dado que la eficiencia no aumenta haciendo que el victimario negligente pague daños a la víctima negligente, el derecho común permitía tradicionalmente que el costo del accidente se quedara donde caía, a fin de minimizar los costos de administración del sistema legal. Un pago de transferencia, del victimario a la víctima, costará algo pero no aumentará la riqueza de la sociedad creando incentivos para el comportamiento eficiente". Richard Posner, óp. cit., 281.

46 Richard Posner, óp. cit., 282.

47 Establece el artículo 2537 del Código Civil: "La apreciación del daño está sujeta a reducción, si el que lo ha sufrido se expuso a él imprudentemente”. Sobre el particular pueden consultarse, entre otras, las siguientes sentencias: Corte Suprema de Justicia, Sala de Casación Civil. Sin radicación (M.P. Germán Giraldo Zuluaga. 9 de febrero de 1976); Corte Suprema de Justicia, Sala de Casación Civil. Sin radicación (M.P. Alberto Ospina Botero. 30 de marzo de 1993); Corte Suprema de Justicia, Sala de Casación Civil. Radicación 6063 (M.P. José Fernando Ramírez Gómez. 21 de febrero de 2002); Consejo de Estado, Sala de lo Contencioso Administrativo, Sección Tercera. Radicación 6065 (C.P. Carlos Betancur Jaramillo. 28 de febrero de 1991); Consejo de Estado, Sala de lo Contencioso Administrativo, Sección Tercera. Radicación 6487 (C.P. Daniel Suárez Hernández. 29 de noviembre de 1991); Consejo de Estado, Sala de lo Contencioso Administrativo, Sección Tercera. Radicación 14140 (C.P. Alier Eduardo Hernández Enríquez. 24 de febrero de 2005); Consejo de Estado, Sala de lo Contencioso Administrativo, Sección Tercera. Radicación 15630 (C.P. Ramiro Saavedra Becerra. 14 de 
La ventaja que puede advertirse en este planteamiento, con respecto al anterior, es que existe un incentivo para que todos los agentes sean diligentes, pues su negligencia en cualquier caso le conllevará la asunción de determinado riesgo. Sin embargo, resulta prácticamente imposible que judicialmente pueda establecerse de manera objetiva el grado de participación o incidencia en el perjuicio que tuvo la conducta de la víctima, lo que necesariamente traerá consigo una consideración meramente subjetiva del funcionario judicial; en otros términos, habrá incentivos para que todos los agentes tomen una conducta diligente, no obstante pueda surgir una decisión judicial ineficiente.

Para el caso que nos ocupa, si no atendiéramos a la responsabilidad contractual que como se indicó es la pertinente, sino que nos acogiéramos a la responsabilidad extracontractual, esta norma sería de plena aplicación práctica, y sin embargo no nos permitirá determinar cuál será el grado de diligencia que adoptará cada uno de los agentes, pues cada uno actuará bajo un alto grado de incertidumbre ${ }^{48}$.

Tal como lo anota Bullard,

[e]l problema que enfrentamos puede ser entendido con el Teorema de Coase. Según la primera formulación del mismo, si los costos de transacción son bajos no importa la regla legal que se establezca para llegar a la solución más adecuada y eficiente. Las partes, mediante arreglos contractuales o de mercado encontrarán soluciones satisfactorias que les brinden seguridad adecuada. En cambio, según la segunda formulación, si los costos de transacción son altos sí interesa cuál es la regla legal que elijamos para llegar a la solución eficiente. Así, de no ser posible que las partes lleguen a acuerdos satisfactorios por ser los costos de transacción elevados, la intervención del Estado puede ser necesaria para llegar a una solución satisfactoria.$^{49}$

Sin embargo, sería necesario además establecer mecanismos que permitan eliminar los problemas de riesgo moral, de tal for-

abril de 2005); Consejo de Estado, Sala de lo Contencioso Administrativo, Sección Tercera. Radicación 28211 (C.P. Ruth Stella Correa Palacio. 25 de agosto de 2005).

48 Para Posner los resultados económicos de la culpa contribuyente y la culpa comparativa son los mismos, no obstante que en el último caso se generan costos de transacción adicionales que tienden a la ineficiencia. Cfr. Richard Posner, óp. cit., 282-287.

49 Alfredo Bullard González, La fábula de los tres chanchitos. La seguridad en internet y los nuevos paradigmas contractuales, en Derecho y economía. el análisis económico de las instituciones legales, $2^{\text {a }}$ ed., 674, Palestra Editores, Lima (2006). 
ma que los costos de precaución por parte de la entidad bancaria sean inferiores al costo del riesgo multiplicado por la probabilidad de ocurrencia. En otros términos, generar incentivos para que la precaución sea compartida entre titulares de los medios de pago y emisores de estos, con el objetivo de que la probabilidad de ocurrencia de los siniestros disminuya y el costo de la indemnización lo haga en la misma forma, para que se solucione el problema que bajo la teoría de Hand se esbozó anteriormente.

Corolario de lo anterior sería que, ante la ineficiencia de las causales eximentes de responsabilidad, estas se deben excluir del ámbito regulatorio para el caso que nos ocupa, y en su lugar considerar posibilidades como podría ser, por ejemplo, determinar que en todos los casos la entidad financiera responde, bajo la regla de responsabilidad objetiva, pero establecer una proporción máxima de indemnización, para que el titular del medio de pago asuma igualmente una parte del perjuicio ${ }^{50}$. Indiscutiblemente, la determinación exacta en torno a la eficiencia de la solución dependerá de cálculos matemáticos que permitan evidenciar el monto eficiente de indemnización, análisis que desborda los objetivos del presente escrito.

50 Para Bullard, el propio mercado se encarga que los proveedores de servicios a través de internet generen mecanismos de seguridad en sus transacciones. Afirma el profesor peruano: "La seguridad de una transacción, cuando es deseada por los consumidores, reduce los costos de transacción. Si un proveedor encuentra formas baratas de brindar seguridad a sus consumidores sabe que podrá reducir la tasa de descuento por riesgo e incertidumbre que este incorpora a la transacción. Si ello es así, sabe que venderá más y más caro. Como su objetivo es vender más tendrá incentivos para encontrar formas de seguridad que estén justificadas por el tipo de transacción involucrada en cada caso. Es decir, que existen incentivos para generar sistemas privados de seguridad que reduzcan la tasa de descuento que el consumidor aplica a ciertas transacciones". Alfredo Bullard González, óp. cit., 675. 


\section{CONCLUSIONES}

De conformidad con los planteamientos esbozados a lo largo del presente escrito, podemos concluir lo siguiente:

a. No existe claridad en torno a la posibilidad de establecer un régimen de responsabilidad objetiva con base en la teoría de los riesgos, bajo el ordenamiento jurídico colombiano.

Las normas jurídicas que rigen la responsabilidad civil en Colombia no estipulan de manera expresa ninguna disposición de la que pueda concluirse, sin que se genere duda alguna, que al menos en materia bancaria la responsabilidad por fraudes electrónicos es objetiva.

Sin embargo, varias aproximaciones doctrinales y jurisprudenciales advierten no solo esa posibilidad, sino que con fundamento en ella consideran que es aplicable en diversos escenarios, como el bancario.

b. No obstante lo anterior, el régimen de responsabilidad objetiva, bajo los supuestos planteados, no resulta ser la solución más eficiente.

Adicionalmente, tal escenario generaría consecuencias no deseadas desde el punto de vista social, como el aumento del precio en los servicios financieros, con la consecuente disminución de las cantidades demandadas, o eventualmente la decisión de algunos oferentes, en este caso entidades financieras, de dejar de prestar el servicio.

c. Ante la referida ineficiencia, se requiere una serie de ajustes en el régimen planteado que permitan eliminar los problemas de riesgo moral y asignación de las cargas, que no son viables en este momento, a la luz de las reglas de responsabilidad establecidas en nuestro ordenamiento jurídico. Sería entonces apenas una breve opinión para ser analizada en aras de su recogimiento normativo.

d. Bajo las restricciones normativas actualmente existentes, la solución más eficiente es mantener el régimen subjetivo de responsabilidad contractual bajo la culpa presunta, que genera algunos desincentivos a conductas constitutivas de riesgo moral y, en todo caso, distribuye de mejor manera los riesgos. 


\section{REFERENCIAS}

\section{Doctrina}

Alfredo Bullard González, La fábula de los tres chanchitos. La seguridad en internet y los nuevos paradigmas contractuales, en Derecho y economía. el análisis económico de las instituciones legales, $2^{\mathrm{a}}$ ed., 674, Palestra Editores, Lima (2006).

Andrés Mariño López, Responsabilidad contractual por utilización indebida de tarjeta de crédito, tesis doctoral, Universidad Autónoma de Barcelona, Barcelona 134 (2003).

Asociación Nacional de Instituciones Financieras - ANIF, Informe Semanal No. 1065 del 22 de marzo de 2011. Disponible en: www.anif.co.

Carlos Pablo Márquez Escobar, Anotaciones sobre análisis económico del derecho, vol. I, Pontificia Universidad Javeriana, Bogotá D.C. (2005).

Confederación Colombiana de Cooperativas - Confecoop, Observatorio Cooperativo No. 12, Las tasas de interés en el sector cooperativo colombiano. Disponible en: www.confecoop.coop (diciembre de 2010).

Edmund Kitch, Los fundamentos intelectuales del análisis económico del derecho, en Derecho y economía: una revisión de la literatura, 51, Fondo de Cultura Económica, México D.F. (2000).

Francisco Ternera Barrios \& Fabricio Mantilla Espinosa, La responsabilité objective $d u$ fati (sic) des activités dangereuses, Revista Estudios Socio-Jurídicos, Universidad del Rosario, Bogotá D.C. (julio-diciembre de 2004).

Gregory Mankiw, Principios de economía, $3^{\mathrm{a}}$ ed., McGraw Hill, Madrid (2004).

Hal Varian, Microeconomía intermedia, $8^{\mathrm{a}}$ ed., Antoni Bosch, Barcelona (2010).

Héctor García Santiago, Los medios de pago: evolución y responsabilidad de sus emisores, en Estudios jurídicos sobre comercio electrónico, Pontificia Universidad Javeriana - Cámara de Comercio de Bogotá, Bogotá D.C. (2006).

Horacio Roberto Granero, Aspectos legales y prácticos de la implementación de una infraestructura bancaria de firma digital. Disponible en: www.derechoybanca. com (recuperado el $1^{\circ}$ de diciembre de 2007).

Juan Andrés Orrego Acuña, Apuntes de responsabilidad objetiva, 6. Disponible en: www. juanandresorrego.cl (recuperado el 5 de diciembre de 2007).

Leandro Emilio Toscano, El derecho bancario frente a las nuevas tecnologías. Los riesgos derivados de su aplicación, 33 Enfoque integral y práctico de la cuestión. Disponible en: www.derechoybanca.com (recuperado el $1^{\circ}$ de diciembre de 2007).

Lewis Kornhauser, El nuevo análisis económico del derecho: Las normas jurídicas como incentivos, en Derecho y economía: una revisión de la literatura, 19-50, Fondo de Cultura Económica, México D.F. (2000).

Manuel Guillermo Sarmiento García, La Teoría del riesgo y la responsabilidad civil, en Estudios de responsabilidad civil, 203-224, Universidad Externado de Colombia, Bogotá D.C. (2003). 
Mitchell Polinsky \& Steven Shavell, Should liability be based on the harm to the victim or the gain to the injurer?, National Bureau of Economic Research - Nber, Nber Working Paper Series, Working Paper No. 4586, Cambridge (1993).

Ricardo Bernal Fandiño, Concentración y competencia en el sistema financiero crediticio colombiano en la última década, Banco de la República, Borradores de economía, No. 432, Bogotá D.C. (2007).

Richard Posner, El análisis económico del derecho, $2^{\mathrm{a}}$ ed. en español, Fondo de Cultura Económica, México, D.F., 279 (2007).

, El movimiento del análisis económico del derecho, en Derecho y economía: una revisión de la literatura, 227, Fondo de Cultura Económica, México D.F. (2000).

Robert Frank, Microeconomía intermedia, $7^{\mathrm{a}}$ ed., McGraw Hill, México (2009).

Ronald Coase, El problema del costo social, en Derecho y economía: una revisión de la literatura, Fondo de Cultura Económica, México D.F. (2000).

Stephen Rhoades, The Herfindahl-Hirschman Index, 79 Federal Reserve Bulletin (marzo de 1993).

Superintendencia de Bancos y Seguros del Ecuador, Dirección Nacional de Estudios, Subdirección de Estudios, Sistema Financiero Sensibilidad de la Demanda por Créditos - Tasa de Interés, período diciembre de 2010-diciembre de 2011. Disponible en: www.sbs.gob.ec.

William Mills, Contributory Negligence. Disponible en: www.ncatl.org (recuperado el 22 de enero de 2008).

\section{Normativa nacional}

Circular Externa 038 de 2011 [Superintendencia Financiera de Colombia]. Sobre información a los consumidores financieros. 6 de septiembre de 2011.

Circular Externa 039 de 2011 [Superintendencia Financiera de Colombia]. Sobre cláusulas y prácticas abusivas. 6 de septiembre de 2011.

Circular Externa 042 de 2012 [Superintendencia Financiera de Colombia]. Por medio de la cual se incorporan algunas modificaciones al Capítulo Décimo Segundo del Título Primero de la Circular Básica Jurídica, en materia de requerimientos mínimos de seguridad y calidad para la realización de operaciones. 4 de octubre de 2012.

Circular Externa 052 de 2007 [Superintendencia Financiera de Colombia]. Sobre requerimientos mínimos de seguridad y calidad en el manejo de información a través de medios y canales de distribución de productos y servicios para clientes y usuarios. 25 de octubre de 2007.

Código Civil [C.C.]. Ley 57 de 1887 (Colombia).

Ley 1328 de 2009. Por la cual se dictan normas en materia financiera, de seguros, del mercado de valores y otras disposiciones, D.O. No. 47.411 del 15 de julio de 2009 (Colombia). 


\section{Jurisprudencia nacional}

Consejo de Estado, Sala de lo Contencioso Administrativo, Sección Tercera. Radicación 13477 (C.P. María Elena Giraldo Gómez. 2 de mayo de 2002).

Consejo de Estado, Sala de lo Contencioso Administrativo, Sección Tercera. Radicación 6065 (C.P. Carlos Betancur Jaramillo. 28 de febrero de 1991).

Consejo de Estado, Sala de lo Contencioso Administrativo, Sección Tercera. Radicación 6487 (C.P. Daniel Suárez Hernández. 29 de noviembre de 1991).

Consejo de Estado, Sala de lo Contencioso Administrativo, Sección Tercera. Radicación 14140 (C.P. Alier Eduardo Hernández Enríquez. 24 de febrero de 2005).

Consejo de Estado, Sala de lo Contencioso Administrativo, Sección Tercera. Radicación 15630 (C.P. Ramiro Saavedra Becerra. 14 de abril de 2005).

Consejo de Estado, Sala de lo Contencioso Administrativo, Sección Tercera. Radicación 28211 (C.P. Ruth Stella Correa Palacio. 25 de agosto de 2005).

Corte Constitucional, Sentencia C-453 de 2002 (M.P. Álvaro Tafur Galvis. 12 de junio de 2002).

Corte Constitucional, Sentencia T-556 de 2003 (M.P. Clara Inés Vargas Hernández. 3 de julio de 2003).

Corte Suprema de Justicia, Sala de Casación Civil, Expediente 11001-3103-038-200101054-01 (M.P. William Namén Vargas. 24 de agosto de 2009).

Corte Suprema de Justicia, Sala de Casación Civil, sin radicación (M.P. Germán Giraldo Zuluaga. 9 de febrero de 1976).

Corte Suprema de Justicia, Sala de Casación Civil, sin radicación (M.P. Alberto Ospina Botero. 30 de marzo de 1993).

Corte Suprema de Justicia, Sala de Casación Civil, radicación 6063 (M.P. José Fernando Ramírez Gómez. 21 de febrero de 2002).

Corte Suprema de Justicia, Sala de Casación Laboral, radicación 20186 (M.P. Luis Javier Osorio López. 8 de agosto de 2003).

Tribunal Superior del Distrito Judicial de Bogotá, Sala Civil. Radicación 110013103008200101281-01 (M.P. Ana Lucía Pulgarín Delgado. 20 de abril de 2006).

\section{Normativa internacional}

Código Civil [C.C.]. Ley 340 de septiembre 25 de 1869 (Argentina).

\section{Jurisprudencia internacional}

Cour de Cassation, Assemblée Plénière, Arrêt No. 559 du 29 juin 2007. Disponible en: www.courdecassation.fr (recuperado el $1^{\circ}$ de diciembre de 2007). 